ARTÍCULO CORTO DE INVESTIGACIÓN DOI: 10.47864/SE(50)2020p26-30_115
Sociedad Colombiana de la Ciencia del Suelo

\title{
DETERMINACIÓN DE COBRE UNIDO A LA FRACCIÓN DE ÁCIDOS FÚLVICOS DE UN SUELO ANDISOL DEL CAUCA MEDIANTE VOLTAMPEROMETRÍA
}

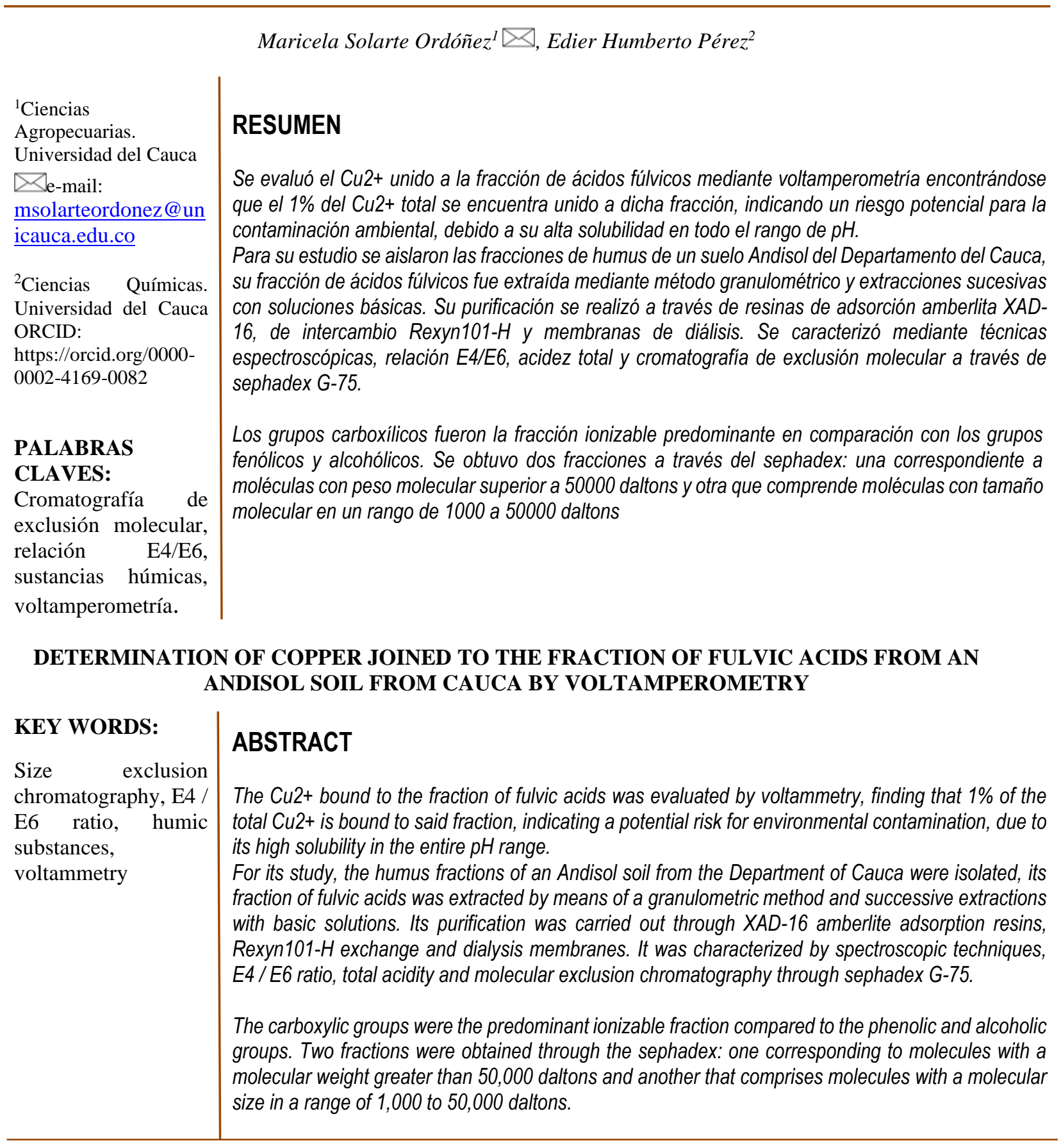




\section{INTRODUCCIÓN}

Algunos metales que se encuentran naturalmente en el suelo o que son adicionados como fertilizantes o agroquímicos, son retenidos como complejos insolubles volviéndose indisponible para las plantas. Por otro lado, muchos metales que ordinariamente se convertirían en precipitados insolubles, a valores de $\mathrm{pH}$ de los suelos agrícolas productivos comprendidos entre: 5,6 a 6,5, se mantienen en solución a través de la quelatación (Stevenson 1985).

Los funguicidas a base de cobre son muy utilizados como bactericida y biocida, ejerciendo el control de bacterias fitopatógenas en los cultivos de café, para contrarrestar la roya (Hemileia vastatrix).

$\mathrm{El}$ repetitivo uso de la mezcla $\mathrm{CuSO}_{4} \cdot 5 \mathrm{H}_{2} \mathrm{O}+\mathrm{Ca}(\mathrm{OH})_{2}$, como funguicida, y el uso de abonos orgánicos, han conducido a casos de toxicidad de las plantas por cobre (Schulte 1999).

El cobre es considerado el menos móvil de los oligoelementos del suelo, por lo general, se inmoviliza en los primeros $20 \mathrm{~cm}$ del perfil. Algunos de los factores que influyen en la adsorción del cobre en los suelos son: $\mathrm{El} \mathrm{pH}$, el contenido de carbonatos, la capacidad de intercambio catiónico (CIC), la cantidad de arcillas y de la cantidad y calidad de la materia orgánica como factores principales.

Por otro lado, los Ácidos Fúlvicos (AF), que conforman la parte soluble de la materia orgánica y que se presentan en mayor proporción que los ácidos húmicos en compost inmaduros, tienen un papel importante en la solubilización y transporte de iones metálicos en suelos y aguas, además actúan como modificadores de la química de iones metálicos. Los AF tienen una variedad de estructuras aromáticas y alifáticas con altos contenidos de grupos oxigenados particularmente ácidos carboxílicos e hidroxilos (Bravo et al. 2016; Piccolo 2001). Estos grupos pueden estar protonados o desprotonados en un rango de $\mathrm{pH}$ entre 3 y 9, habilitando a los AF a comportarse como un polielectrolito (MacCarthy 2001; Conte y Piccolo 1999). Los grupos oxigenados, particularmente carboxílicos y fenólicos se asocian a iones como $\mathrm{Al}^{3+}$, $\mathrm{Ca}^{2+}, \mathrm{Mg}^{2+}, \mathrm{Cu}^{2+}, \mathrm{Fe}^{2+}, \mathrm{Cd}^{2+}, \mathrm{Zn}^{2+}, \mathrm{y} \mathrm{Ni}^{2+}$, entre otros. Mientras que los cationes monovalentes como $\mathrm{Na}^{+} \mathrm{y} \mathrm{K}^{+}$ pueden formar enlaces electrostáticos con grupos aniónicos simples sobre el AF, los iones metálicos divalentes pueden ser complejados en dos sitios aniónicos adyacentes, formando un anillo quelato. Esta asociación es generalmente más fuerte que la formada a través de un solo sitio (Stevenson 1985; Bornemisza et al. 1996).

La cuantificación del $\mathrm{Cu}^{2+}$ se realiza mediante técnicas electroquímicas como la voltamperometría por su alta sensibilidad, rangos de concentraciones lineales amplio para especies orgánicas e inorgánicas $\left(10^{-12}\right.$ a $\left.10^{-1} \mathrm{M}\right)$, la diversidad de solventes y electrolitos útiles, y amplio rango de temperaturas de trabajo que permiten análisis rápidos (segundos) y la determinación simultánea de varios analitos, además de permitir la determinación de parámetros cinéticos y mecánicos (Skoog et al. 2003)

Para la cuantificación de $\mathrm{Cu}^{2+}$ se utilizó la voltamperometría de redisolución anódica en la cual durante una pre-electrólisis a un adecuado potencial aplicado, los iones $\mathrm{Cu}^{2+}$ son reducidos y amalgamados en un electrodo de gota de mercurio (HMDE), para luego oxidar el analito contenido en la gota. Durante esta oxidación, la corriente alcanza un valor máximo que es proporcional a la cantidad de analito que se ha depositado (Ryley y Watson 1987). Las técnicas voltamperométricas se emplean para la determinación cuantitativa de diferentes metales en solución, estas técnicas implican la aplicación de un potencial (E) a un electrodo de trabajo frente a un electrodo de referencia y la supervisión de la corriente que resulta (I), la cual se mide entre el electrodo de trabajo y un electrodo auxiliar de platino.

En este trabajo se evalúa electroquímicamente la cantidad de cobre que esta quelatado en los ácidos fúlvicos previa Extracción y purificación. Esto con el propósito de contribuir a elucidar el destino ambiental de algunos metales utilizados como fungicidas.

\section{MATERIALES Y MÉTODOS}

\section{Sitios de Muestreo}

Las muestras de suelo se tomaron en el Departamento del Cauca, Municipio de Cajibío, Vereda La Aurelia, altitud de 1740 metros sobre el nivel del mar.

Una vez ubicada la Unidad de Muestreo seleccionada con base a topografía y cultivo de café, se realizó un muestreo al azar en zig-zag, a una profundidad de $30 \mathrm{~cm}$, en un área de $100 \mathrm{~m}^{2}$, tomando 20 submuestras, se mezclaron homogéneamente para formar una muestra compuesta y obtener una muestra representativa del sitio. La muestra fue almacenada en bolsas negras de polietileno y llevada al laboratorio, donde fue secada al aire y tamizada por malla de $2 \mathrm{~mm}$, posteriormente fue caracterizada de acuerdo a metodología previamente estandarizada (Bravo y Giraldo 2003).

\section{Extracción y Purificación de los Ácidos Fúlvicos}

Inicialmente se obtiene la Materia orgánica humificada $(\mathrm{MOH})$, suspendiendo el suelo seco y tamizado en agua, en relación 18:100, agitando la suspensión durante 16 horas en presencia de bolas de cristal. $\mathrm{La}$ suspensión se somete a separación granulométrica en húmedo en un tamizador eléctrico, la fracción menor a $53 \mu \mathrm{m}$ corresponde a la $\mathrm{MOH}$. Para obtener los ácidos 
fúlvicos se hacen extracciones sucesivas de la $\mathrm{MOH}$ con tres soluciones básicas $0.1 \mathrm{~N}$ de $\mathrm{Na}_{2} \mathrm{~B}_{4} \mathrm{O}_{7} .10 \mathrm{H}_{2} \mathrm{O}$, $\mathrm{Na}_{2} \mathrm{P}_{2} \mathrm{O}_{7} .10 \mathrm{H}_{2} \mathrm{O}$ y de $\mathrm{NaOH}$, usando los procedimientos recomendados por la Sociedad Internacional de Sustancias Húmicas (Sutton y Sposito 2005), y estandarizados en el Laboratorio de Agroquímica de la Universidad del Cauca (Mosquera y Bravo 2006 ; Mosquera et al. 2007) Los sobrenadantes de estas extracciones, en donde se encuentran las fracciones de ácido húmicos y ácidos fúlvicos, se someten a tratamiento con sulfato de sodio para flocular y separar las arcillas ligadas a dichas fracciones, mediante centrifugación a 6000 rpm.

Los ácidos fúlvicos se extrajeron de acuerdo a la metodología propuesta por Davila 2002 y Muñoz 2004. Obteniéndose una solución amarilla correspondiente a los ácidos fúlvicos.

La purificación de estos ácidos se realizó inicialmente concentrando la solución a través de una columna de amberlita XAD-16 y posterior elusión con $\mathrm{NaOH} 0.7$ $\mathrm{M}$ obteniéndose los ácidos en forma de fulvatos de sodio, estos últimos se pasaron a través de una columna de intercambio iónico Rexyn 101- H, por último se pasaron a través de membranas de diálisis de 4000D hasta $\mathrm{pH} 4$ y conductividad menor de $150-180 \mu \mathrm{s}$.

\section{Caracterización de los Ácidos fúlvicos}

Para caracterizar los ácidos fúlvicos purificados inicialmente se determinó la Acidez total, titulando con volumen fijo de $0.05 \mathrm{~mL}$ de hidróxido de sodio en un Titulador automático universal METROHM E-70, previo intercambio con $\mathrm{KCl}$ para determinar los grupos carboxilos e hidroxilos fenólicos disociados. Así se determinó el grado de sustitución y en consecuencia la capacidad de intercambio de estas macromoléculas (Colombo et al. 2007) Posteriormente se realizó un Fraccionamiento, con el objeto de fraccionar la macromolécula de carácter heterogénea, en fracciones más homogéneas, se hace una filtración a través de sephadex G-75, con un rango de fraccionamiento entre 1000 y 50000 daltons obteniéndose fracciones de acuerdo al tamaño molecular. Por último se determinó la Relación $\boldsymbol{E}_{4} / \boldsymbol{E}_{6}$, disolviendo los ácidos fúlvicos en $\mathrm{NaHCO}_{3} \quad 0.5 \mathrm{~N}$ y se determinó la densidad óptica a $465 / 665 \mathrm{~nm}$

\section{Determinación de Cobre unido a la fracción de ácidos fúlvicos.}

En la determinación del cobre total, el unido a los ácidos fúlvicos como en las fracciones provenientes de la separación por sephadex G-75 se realizaron digestiones con mezcla perclórico-nítrico $(3: 1)$ para obtener el cobre en su forma libre, posteriormente se hizo la cuantificación mediante un polarógrafo analizador de trazas 746 VA - STAND 747 VA METROHM, con los electrodos Multimodo de Mercurio (MME), Electrodo de Referencia $\mathrm{Ag} / \mathrm{AgCl} / \mathrm{KCl} 3.0 \mathrm{~mol} / \mathrm{L}$ y Electrodo Auxiliar de Platino (Pt) siguiendo los parámetros establecidos en la tabla 1.

El factor de regresión obtenido para la curva patrón fue de 0.999. La repetitividad y la reproducibilidad presentaron desviaciones estándar relativas (RSD) menores de $2.5 \%$. El límite de cuantificación se determinó en $0.0098 \mathrm{ppm}$ de $\mathrm{Cu}^{2+}$ y el límite de detección en 0.0030 ppm

Tabla 1. Parámetros óptimos para determinar $\mathrm{Cu}^{2+}$ en un suelo mediante voltamperometría de redisolución anódica

\begin{tabular}{ll}
\hline PARÁMETROS & \\
\hline Potencial de electrolisis & $-800 \mathrm{mV}$ \\
Tiempo de electrolisis & $150 \mathrm{~s}$ \\
Tamaño de gota de $\mathrm{Hg}$ & 4.0 \\
Potencial inicial & $-300 \mathrm{mV}$ \\
Potencial final & $250 \mathrm{mV}$ \\
Velocidad de agitación & $2000 / \mathrm{min}$ \\
Potencial de reconocimiento & $5 \pm 20 \mathrm{mV}$ \\
Tiempo de barrido & $28.5 \mathrm{~s}$ \\
Purga $\mathrm{N}_{2}$ & $300 \mathrm{~s}$ \\
Electrodo de trabajo & $\mathrm{Gota}$ de mercurio \\
Electrodo de referencia & $\mathrm{Ag} / \mathrm{AgCL}$ \\
Electrodo auxiliar & $\mathrm{Pt}$ \\
Modo & Onda cuadrada \\
\hline
\end{tabular}

\section{RESULTADOS Y DISCUSIÓN}

\section{Caracterización de los Ácidos Fúlvicos}

Acidez total. En la figura 1, se observa tres puntos de equivalencia indicando la presencia de tres grupos ácidos titulables. El punto A, a $0,089 \mathrm{~mL}$ con un $\mathrm{pKa}=$ 4,2 , el punto $\mathrm{B}$, a $0,145 \mathrm{~mL}(\mathrm{pKa}=4.4)$ y el último punto $\mathrm{C}$, a $0.201 \mathrm{~mL}(\mathrm{pKa}=4,7)$. Los $\mathrm{pKa}$ encontrados en la titulación de los AF purificados oscilan en un rango de 4,4 $\pm 0,25$ que corresponden según la literatura a pKa de grupos de ácidos carboxílicos (Morrinson y Boyd 1990). Estos ácidos pueden ser de tipo mono- y dicarboxílicos en cantidades iguales como establece Simpson y colaboradores, en su estudio de sustancias húmicas Simpson et al. (2001). No se detectan grupos fenólicos ni alcohólicos indicando que la acidez de estos ácidos corresponde en su mayoría a grupos de ácidos carboxílicos. 


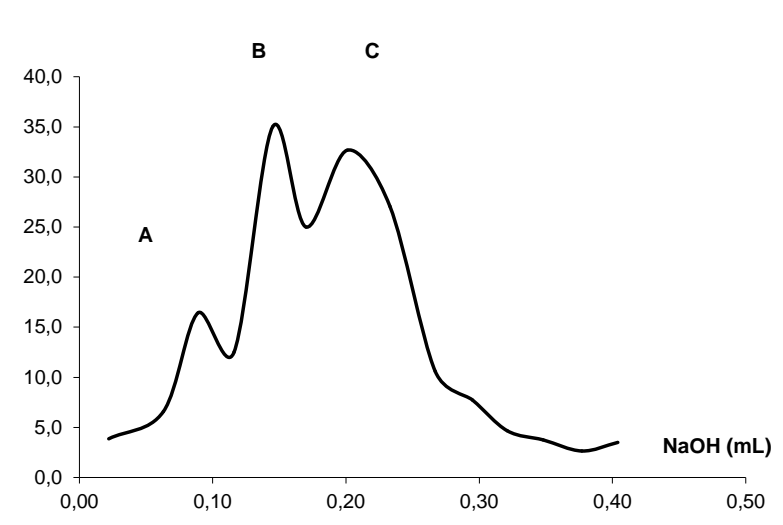

Figura 1. Primera derivada del $\mathrm{pH}$ con respecto al volumen promedio de $\mathrm{NaOH}$ agregado en la titulación de $5 \mathrm{~mL}$ de ácidos fúlvicos purificados

Fraccionamiento. En la figura 2 se observan dos fracciones bien definidas: FI y FII, en donde FI corresponde a la fracción excluida y consiste en moléculas grandes con alto peso molecular superior o igual a 50000 daltons y representa el $38 \%$ de los ácidos fúlvicos eluidos; mientras que, la fracción FII comprende a la fracción retenida, y es la fracción más abundante correspondiente al $62 \%$, consiste de moléculas con tamaño molecular en un rango de 1000 a 50000 daltons

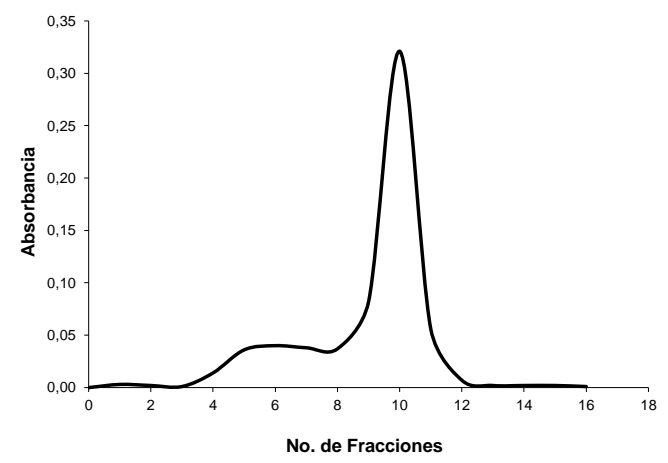

Figura 2. Elución de los ácidos fúlvicos purificados a través de sephadex G-75.

Relación $\boldsymbol{E}_{4} / \boldsymbol{E}_{6}$. El valor obtenido para esta relación fue de 10, para AF extraídos de MO de suelos ándicos, esta magnitud es una relación del grado de condensación de los AF, una relación baja es indicativa de un alto grado de condensación de componentes fúlvicos aromáticos, por otro lado, un valor alto refleja un bajo grado de condensación e infiere la presencia de estructuras alifáticas (IGAC 2006).

Determinación de Cobre total, Cobre en ácidos fúlvicos y en sus fracciones.

El $\mathrm{Cu}^{2+}$ se encontró en una concentración de $0.24 \pm$ $0.016 \mathrm{ppm}$ en los ácidos fúlvicos que corresponde al $1 \%$ del $\mathrm{Cu}^{2+}$ total $(46.61 \mathrm{ppm} \pm 1.630)$ siendo este soluble pero no disponible para la planta puesto que está quelatado por la fracción fúlvica, sin embargo puede pasar por percolación al nivel freático o a los cuerpos de agua.

La unión del $\mathrm{Cu}^{2+}$ en la fracción de ácidos fúlvicos se atribuye principalmente a la quelatación de este catión por grupos carboxílico presentes en los AF. Como se reportó anteriormente en la titulación de los ácidos fúlvicos con $\mathrm{NaOH}$ se obtuvieron valores de $\mathrm{pKa}$ en un rango de $4.4 \pm 0.25$ correspondientes a ácidos de este tipo.

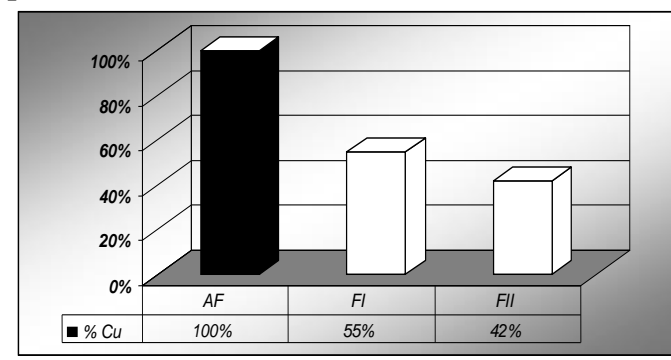

Figura 3. Distribución del $\mathrm{Cu}^{2+}$ en las fracciones de ácidos fúlvicos purificados.

En la figura 3, se observa que la fracción I que corresponde a la de mayor grado de condensación y de mayor peso molecular presenta mayor contenido de $\mathrm{Cu}^{2+}$ siendo 1,3 veces superior al contenido la fracción II; ratificando que entre mayor condensación presente la MO, mayor será la posibilidad de complejar metales.

\section{CONCLUSIONES}

La titulación de los Ácidos Fúlvicos mostró que la acidez se debe principalmente a la presencia de grupos $-\mathrm{COOH}$, los cuales influyen en la quelatación del $\mathrm{Cu}^{2+}$ por parte de estas moléculas.

La cromatografía de exclusión por tamaño, a través de sephadex G-75, de la fracción de ácidos fúlvicos, condujo a dos fracciones en donde, predomina la FII $(62 \%)$ con una relación $\mathrm{E}_{4} / \mathrm{E}_{6}$ de 11,66 correspondiente a estructuras poco condensadas o con más estructuras alifáticas. Mientras que la FI con un porcentaje del 38 $\%$ presenta una relación $\mathrm{E}_{4} / \mathrm{E}_{6}$ de 7,75 indicando mayor grado de condensación.

La unión del $\mathrm{Cu}^{2+}$ en la fracción de ácidos fúlvicos se puede atribuir principalmente a la quelatación de este catión por estructuras de tipo carboxílico y puede llegar a ser contaminante por percolación a los cuerpos de agua.

\section{REFERENCIAS}

Bornemisza, E.; Cabalceta G.; D'ambrosio A. (1996). Evaluación de cobre disponible en andisoles e inceptisoles de Costa Rica plantados de café. Agronomía Costarricense 20(2): 125-133. 
Bravo I.; Giraldo E. (2003). Manual de prácticas de química agrícola: Análisis de suelos. Departamento de Química, Facultad de Ciencias Naturales, Exactas y de la Educación, Universidad del Cauca.

Bravo, I.; Martinez, C.; Pérez, E. Química de la materia orgánica de andisoles altoandinos: Principios básicos y resultados de investigación. Popayán. Universidad del Cauca. 2016. p 138.

Colombo, S. M.; Abate, G.; Lbo, Dos Santos. ; Masini, J. C. (2007). Propiedades ácido base e de complexação de ácidos húmico e fúlvico isolados de vermicomposto. Química Nova, v. 30, p. 1261-1266.

Conte, P.; Piccolo, A. (1999). Conformational arrangement of dissolved humic substances. Influence of solution composition on association of humic molecules Environ. Sci. Technol., 33. P 1682-1690

Dávila J.R. (2002). Caracterización preliminar de Ácidos Fúlvicos de dos suelos Colombianos: Andisol del Cauca y Oxisol del Amazonas (trabajo de grado). Universidad del Cauca, Facultad de Ciencias Naturales, Exactas y de la Educación, Departamento de Química, Popayán.

IGAC. Instituto Geográfico Agustín Codazzi. Métodos analíticos de laboratorio de suelos. $6^{\mathrm{a}} \mathrm{Ed}$. Imprenta Nacional de Colombia, 2006. p 337-369.

Mac Carthy, P. (2001). The principles of humic substances. Soil Science.166 (11): 738-751.

Morrison, R. y Boyd, R. Química Orgánica 5ed. Mexico: Addison -Wesley Iberoamericana. 1999. p 920-950.

Mosquera C. y Bravo I. (2006). Comportamiento de los ácidos húmicos en medio básico. Suelos Ecuatoriales. 36(1): 36-42.

Mosquera, C.; Bravo, I.; Hanser E. (2007). Comportamiento estructural de la Ácidos Húmicos Obtenidos de un Suelo Andisol del departamento del Cauca. Revista Colombiana de Química 36(1): 31-41.

Muñoz, B. (2004). Extracción y caracterización preliminar de huminas de un suelo andisol del departamento del Cauca. (trabajo de grado)Universidad del Cauca, Facultad de Ciencias Naturales, Exactas y de la Educación, Departamento de Química, Popayán.

Piccolo, A.The supramolecular structure of humic substancesSoil Sci. (2001), 166, 810-832.

Ryley, T. y Watson, A. 1987. Polarography and other voltammetric Methods. London: Acol, Thames Polytechnic. p. 159-193.
Schulte, E.E.; Kelling, K.A. (1999). Soil and applied Copper. Understanding plant Nutrients A 2527. Disponible en Internet: http://cecommerce.uwex.edu/pdfs/A2527.PDF

Simpson A.J.; burdon J.; Raham C.L. (2001). Interpretation of heteronuclear and multidimensional NMR spectroscopy of humic substances. Eur. J. Soil Sci, 52, 495-509.

Skoog D.A.; West D.M.; Y holler F.J. Química Analítica. 7a Ed. México: McGraw-Hill.2003.

Stevenson, F.J. (1985). Cycles of Soil. Carbon, Nitrogen, Phosphorus, Sulfur, Micronutrients. Department of Agronomy, University of Illinois. New York: A Wiley-Interscience publication. p 17-99.

Sutton, R.; Sposito, G.; (2005). Molecular structure in soil humic substances: The new view. Environ. Sci. Technol., 39. P 9009 